\title{
Quality of life in individuals living with HIV/AIDS attending a public sector antiretroviral service in Cape Town, South Africa
}

\author{
Mweete D Nglazi ${ }^{1 *+}$, Sacha J West ${ }^{2 \dagger}$, Joel A Dave ${ }^{3}$, Naomi S Levitt ${ }^{3,4}$ and Estelle V Lambert ${ }^{1}$
}

\begin{abstract}
Background: Health related quality of life (HRQOL) is an important outcome helping to understand the impact of antiretroviral therapy (ART). We examined and compared the HRQoL in relation to ART status among HIV-infected patients in a public sector service in Cape Town, South Africa. In addition, we aimed to examine the relationship between ART status and HRQOL according to CD4 count strata.
\end{abstract}

Methods: A cross sectional study sample of 903 HIV-infected patients who were categorized as not receiving ART (ART-naïve) or receiving first-line ART for $>6$ months (ART). HRQoL outcomes were compared in the two groups. HRQoL was assessed using the EQ-5D (five domains) and Visual Analogue Scale (EQ-5D VAS).

Results: Of the total sample, 435 were categorised as ART naive (76\% women) and 468 were on ART (78\% women). There were no significant associations between groups for most of the EQ-5D domains, however ART-naïve experienced a significantly greater problem with mobility than the ART group. Being ART-naïve (adjusted odds ratio (aOR) 3.08 95\% confidence interval (Cl) 1.63- 7.89) and obese 2.78 (95\% Cl 1.24- 6.22) were identified as predictors for increased mobility problems in multivariate analysis. In addition, receiving ART (5.61 difference; $95 \% \mathrm{Cl} 2.50$ - 8.72) and having some source of income $(4.76 ; 95 \% \mathrm{Cl} 1.63$-7.89) were identified as predictors for a higher EQ-5D VAS score. When grouped according to CD4 count strata, there were no significant difference between groups for most of the EQ-5D domains, however the ART-naive group indicated having significantly greater problems under the CD4 count of $>500$ cells $/ \mu \mathrm{L}$ in the anxiety/depression domain (22.4\% vs $8.8 \%, \mathrm{p}=0.018$ ) and significantly lower EQ-5D VAS scores under the CD4 counts

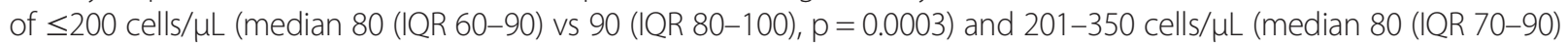
vs 90 (80-100), $p=0.0004)$ compared to ART group.

Conclusions: HRQoL (self-rated health state) was improved with ART use, including those with immunocompromised status, which may be relevant to the public sector ART program in South Africa.

Keywords: Health related quality of life, HIV or AIDS, Health outcomes, EQ-5D

\section{Background}

Human immunodeficiency virus (HIV) is a global epidemic with 35 million people living with HIV/AIDS worldwide, the majority of whom reside in resource-poor countries. By 2012, sub-Saharan Africa accounted for 70\% of the universal total, with South Africa home to the

\footnotetext{
* Correspondence: mweete.nglazi@gmail.com

${ }^{\dagger}$ Equal contributors

'MRC/UCT Research Unit for Exercise Science and Sports Medicine, Department of Human Biology, University of Cape Town, Cape Town, South Africa

Full list of author information is available at the end of the article
}

largest number of people living with HIV in the world (6.1 million) [1].

The roll out of antiretroviral therapy (ART) has profoundly improved the grave portrayal of this disease in South Africa. The national ART program commenced in 2004 and the latest WHO statistics show that, at the end of 2012, there were an estimated 2150881 HIV-infected people receiving ART in South Africa [2]. However, while ART prolongs the lives of HIV-infected individuals [1], it is associated with a variety of metabolic sequelae, including metabolic abnormalities and morphological body changes [3-5], that may adversely affect quality of life with 
long-term use [6]. There is, therefore, a growing need to understand the impact of ART use and on health-related quality of life (HRQoL).

Numerous studies have examined HRQoL in HIVinfected individuals the impact of ART on HRQoL in HIV infected adults in South Africa [7-12]. These studies have been either cross-sectional or longitudinal designs. A recent cross-sectional study demonstrated a significant association between ART use and improved HRQoL indicators [7]. A second cross-sectional study found an improvement in physical health only [8]. Another study showed less pain and discomfort and fewer problems with self-care, daily activities and general mobility [10]. In addition, longitudinal studies have shown significant improvements in HRQoL during 7 months [9], 12 months [11] and 24 months [12] of follow-up after ART initiation.

There are, however, relatively fewer studies from South Africa that assessed the effect of higher CD4 cell counts on HRQoL $[7,13]$. Bhargava and colleagues [13] found the HRQoL of patients receiving ART increased significantly with improvement in CD4 count . Igumbor and colleagues [7] found weak but significant associations between CD4 cell counts and HRQoL in a cohort of treatment-naïve patients and those who had received ART for 12 months.

Globally, there has been concern about how ARTrelated toxicities may adversely affect HRQoL of HIVinfected individuals. Non-nucleotide reverse transcriptase inhibitors such as stavudine $(\mathrm{d} 4 \mathrm{~T})$ have been shown to be associated with metabolic complications such as dyslipidemias, lipoatrophy, peripheral neuropathy and lactic acidosis [14-25]. Owing to toxicity concerns, the World Health Organization (WHO) in 2010 recommended the replacement of $\mathrm{d} 4 \mathrm{~T}$ with tenofovir (TDF) or zidovudine (AZT) -based first-line regimens which have better safety profiles [26,27].

Despite the World Health Organization recommendation to phase out $\mathrm{d} 4 \mathrm{~T}$, the national ART programs of South Africa and other developing countries continue to use $\mathrm{d} 4 \mathrm{~T}$ as part of their first-line ART regimen. By the end of 2011, 1.1 million people were taking $\mathrm{d} 4 \mathrm{~T}$ regimens globally, the vast majority in resource limited settings in sub-Saharan Africa [28]. Progress in phasing-out $\mathrm{d} 4 \mathrm{~T}$ has been tampered by the higher cost of the alternative drugs AZT and TDF, uncertainties regarding whom to give priority to for phase out, the existence of stockpiles of $\mathrm{d} 4 \mathrm{~T}$ in several countries [28] and the failure of major donors to support the complete elimination of $\mathrm{d} 4 \mathrm{~T}$ [29]. With the lack of full elimination of d4T from first-line regimens in resource-poor countries, there is a need for studies on the impact of d4T-containing firstline ART regimens on HRQoL in order to inform their national ART programs.

Therefore, the objectives of this study were to establish whether there was a difference in the HRQoL in those patients who were not receiving ART compared to those who were on first-line ART (predominantly d4T-containing regimen for longer than 6 months) in public sector treatment program in Cross roads, Cape Town, South Africa. In addition, we aimed to examine the relationship between ART status and HRQoL according to CD4 count strata.

\section{Methods}

\section{Study setting and population}

This study is a cross-sectional secondary analysis of a subset of data collected from a broader study examining the prevalence of metabolic complications of ART in HIV-infected patients, conducted by the Division of Diabetic Medicine and Endocrinology of the University of Cape Town in 2007. The study site was the Crossroads community health clinic in Cape Town which provides HIV care to over 5000 patients. As per national ART guidelines at the time of data collection, adult patients qualified for public sector ART if they had a CD4 count below 200 cells $/ \mu \mathrm{L}$ and symptomatic, and/or WHO Stage four AIDS defining illness (World Health Organisation HIV/AIDS Staging System) [30]. The study population consisted of 435 not yet receiving ART (ART-naïve) and 468 on the South African National Department of Health first-line ART regimen (stavudine (d4T) or zidovudine (AZT), lamuvidine (3TC) and efavirenz (EFV) or neviparine (NVP). At the time of data collection, patients in South Africa only qualified for public sector ART if they had a CD4 count below 200 cells/ $\mu \mathrm{L}$ and symptomatic, and/or WHO Stage four AIDS defining illness (World Health Organisation HIV/AIDS Staging System) [30].

The study cohort was selected due to the fact that $\mathrm{d} 4 \mathrm{~T}$ is stll being used as part of first line regimens in South Africa and other resource-limited countries [2,28] and it is, therefore, important to determine whether the drug has a negative impact on HRQoL.

\section{Sampling technique}

The broader study used convenient sampling technique. Patients were conveniently sampled consecutively from the day list at the Crossroad Community Health clinic; and all patients meeting the inclusion criteria were invited to participate in the study. Study recruitment began in February 2007 with a target sample size of 1650 (Note that the main objectives of the original study from which the study emanates were to estimate and compare the prevalence of metabolic complications in three ART regimen- hence to estimate the prevalence of lipodystrophy at $40 \%$ (an assumption derived from the literature) within an ART regimen with a precision of $4 \%$ a sample size of 557 per ART regimen is needed and to compare the prevalence of lipodystrophy between the three ART regimens using a chi-squared test with 90\% power and 5\% significant level a sample size of 552 was 
needed per ART regimen. A total target sample size of 1650 patients (consisting of 550 per ART regimen) was therefore needed to meet the requirements of both objectives). However, only 1035 patients (approximately $95 \%$ of patients approached) consented to participate in the broader study.

\section{Inclusion criteria}

To participate in the broader study, subjects were 18 years and older and were required not to have changed their ART in the past six months. Exclusion criteria included a history of diabetes mellitus or impaired glucose tolerance, active $\mathrm{TB}$, active acute opportunistic infections, severe diarrhoea ( $>6$ stools/day), known renal failure, pregnancy, or had received glucocorticoid therapy within the past six months.

\section{Measurements}

This study formed part of a larger study examining the metabolic complications of ART in South African HIVpositive patients where subjects underwent an oral glucose tolerance test (OGTT), blood pressure measurements, lipodystrophy questionnaire and a neuropathy examination [31]. Those data therefore will not be reported in this paper.

Table 1 Subject characteristics for ART-naïve and ART groups

\begin{tabular}{|c|c|c|c|c|}
\hline & $\begin{array}{c}\text { Total } \\
(\mathrm{n}=903) \\
\mathrm{N}(\%)\end{array}$ & $\begin{array}{c}\text { ART-naïve } \\
\text { (n= 435) } \\
\text { N (\%) }\end{array}$ & $\begin{array}{c}\text { ART } \\
(n=468) \\
N(\%)\end{array}$ & $P$ value \\
\hline Age, yrs, median (IQR) & $33(29-40)$ & $32(28-38)$ & $35(30-42)$ & $<0.0001$ \\
\hline Female & $697(77.2)$ & $331(76.1)$ & $366(78.2)$ & 0.450 \\
\hline \multicolumn{5}{|l|}{ Education } \\
\hline No education & $58(6.4)$ & $25(5.8)$ & $33(7.1)$ & \multirow[t]{3}{*}{0.654} \\
\hline$\leq$ Grade 12 & $820(90.8)$ & $399(91.7)$ & $421(90.0)$ & \\
\hline$>$ Grade 12 & $25(2.8)$ & $11(2.5)$ & $14(3.0)$ & \\
\hline Housing density (persons/room), median (IQR) & $2(1-3)$ & $2(1-3)$ & $1.5(1-3)$ & 0.002 \\
\hline \multicolumn{5}{|l|}{ Employment } \\
\hline Full or part time & $250(27.7)$ & $115(26.4)$ & $135(28.9)$ & \multirow[t]{3}{*}{0.791} \\
\hline Unemployed & $648(71.8)$ & $317(72.9)$ & $331(70.3)$ & \\
\hline Other & $5(0.6)$ & $3(0.7)$ & $2(0.4)$ & \\
\hline Current smoker & $136(15.1)$ & $75(17.2)$ & $61(13.0)$ & 0.077 \\
\hline Ever drank alcohol & $426(47.2)$ & $226(52.0)$ & $200(42.8)$ & 0.006 \\
\hline CD4 count, cells/ $\mu$ l median (IQR) & $289(184-455)$ & $224(153-437)$ & $318(222-468)$ & $<0.0001$ \\
\hline Previous TB & $379(49.8)$ & $254(64.0)$ & $125(34.3)$ & $<0.001$ \\
\hline \multicolumn{5}{|l|}{ Treatment regimens } \\
\hline d4T 3TC EFV & - & - & $238(51.8)$ & \\
\hline d4T 3TC NVP & - & - & $169(36.3)$ & \\
\hline AZT 3TC EFV & - & - & $11(2.4)$ & \\
\hline AZT 3TC NVP & - & - & $45(9.6)$ & \\
\hline Other & - & - & $2(0.4)$ & \\
\hline \multicolumn{5}{|l|}{ Duration of treatment (months) } \\
\hline$d 4 T$ & - & - & $13.0(8.0-20.0)$ & \\
\hline AZT & - & - & $12.0(7.0-18.5)$ & \\
\hline \multicolumn{5}{|l|}{ Body composition } \\
\hline $\mathrm{BMI}, \mathrm{kg} / \mathrm{m}^{2}$, median (IQR) & $25.2(22.0-29.6)$ & $24.2(21.4-29.0)$ & $26.0(22.9-30.0)$ & 0.0004 \\
\hline Waist-to-hip ratio, mean \pm SD & $0.85 \pm 0.07$ & $0.84 \pm 0.07$ & $0.87 \pm 0.08$ & $<0.01$ \\
\hline Sagittal height, cm, median (IQR) & $19.3(17.0-22.0)$ & $18.3(16.5-21.0)$ & $19.8(17.5-22.5)$ & $<0.0001$ \\
\hline Sum of skinfolds, median (IQR) & $108.8(69.5-158.7)$ & $103.8(64.4-164.1)$ & $111.5(74.1-153.8)$ & 0.557 \\
\hline Calf skinfolds, median (IQR) & $14.6(8.4-21.6)$ & $15.6(9.3-22.6)$ & $13.4(7.8-20.5)$ & 0.012 \\
\hline
\end{tabular}

d4T, Stavudine; AZT,.Zidovudine; 3TC, Lamuvidine; EFV, Efavirenz; NVP, Nevirapine. 


\section{Body Composition Assessment}

The following anthropometric measurements were done in all subjects: weight, height, skinfolds (triceps, biceps, subscapular, supra-iliac, abdominal, thigh and calf), circumferences (waist, hip, arm and thigh) and sagittal abdominal diameter (SAD) [32,33]. All measurements were performed by one trained investigator for consistency of data. All measurements were done in duplicate as previously described $[31,34,35]$. Sagittal abdominal diameter was measured as the distance between the blades of a portable sliding-beam caliper at the level of the iliac crest (L4-5) after a normal expiration with the subject lying in the supine position on a flat, standard, clinic examining bed.

\section{Questionnaire}

A questionnaire was administered face-to-face to all subjects on entry into the study by trained field workers. General and demographic information, measures of socio-economic status, family medical history, clinical conditions and medication, dietary intake, and the use of drugs and toxins (including alcohol and tobacco) was obtained from the questionnaire. A review of subjects' clinical records was done to provide all information on prior ART regimen, time on ART and CD4 count data.

\section{Quality of Life}

HRQoL was assessed using a validated EQ-5D (five domains) tool and Visual Analogue Scale (EQ-5D VAS) [36-38]. The EQ-5D comprises of two components- a questionnaire and a visual analogue scale-EQ-5D VAS). The questionnaire part is a standardised measure of health status that includes five domains regarding quality of daily life, namely mobility, self-care, usual activities, pain and discomfort, and anxiety and depression. Each domain has three levels: no problems, some problems and severe problems. The EQ-5D VAS is used to assess overall current health. A score is recorded on a vertical, visual analogue scale with endpoints: 0 being "worst imaginable health state" to 100 being "best imaginable health state".

\section{Statistical Analysis}

Subject characteristics and HRQoL outcomes were tabulated and stratified by ART status. Proportions were compared for categorical variables. Continuous variables were presented as medians and interquartile ranges unless otherwise stated. All continuous variables were not normally distributed (normality tested using Shapiro-Wilk test) except for waist-to-hip ratio. The Wilcoxon-Rank sum test was used to compare medians and Student's t test to compare means.

The effect of ART status on HRQoL was examined using logistic regression for dichotomous outcome variables (EQ-5D five domains) and linear regression for the continuous outcome variable (EQ-5D VAS score). Each EQ-5D domain were categorised as "no problems" versus "problems" because the number of subjects that reported "severe problems" were very low, and therefore "some and severe problems" were combined to form one "problems" sub-category. The explanatory variable of interest in all models was ART status. Confounding variables were $\mathrm{CD} 4$ count, age, gender, education

Table 2 Health-related quality of life (EuroQol) of ART-naïve and ART groups

\begin{tabular}{|c|c|c|c|c|}
\hline & $\begin{array}{l}\text { Total } \\
\text { N (\%) }\end{array}$ & $\begin{array}{c}\text { ART-naïve } \\
\text { N (\%) }\end{array}$ & $\begin{array}{c}\text { ART } \\
\text { N (\%) }\end{array}$ & $P$ value \\
\hline \multicolumn{5}{|l|}{ Mobility } \\
\hline No problems & $844(93.5)$ & $397(91.3)$ & $444(95.5)$ & \\
\hline Problems & $59(6.5)$ & $38(8.7)$ & $21(4.5)$ & 0.010 \\
\hline \multicolumn{5}{|l|}{ Self Care } \\
\hline No problems & $897(99.3)$ & $430(98.9)$ & $467(99.8)$ & 0.084 \\
\hline Problems & $6(0.7)$ & $5(1.2)$ & $1(0.2)$ & \\
\hline \multicolumn{5}{|l|}{ Usual Activities } \\
\hline No problems & $885(98.2)$ & $423(97.5)$ & $462(98.7)$ & 0.167 \\
\hline Problems & $17(1.9)$ & $11(2.5)$ & $6(1.3)$ & \\
\hline \multicolumn{5}{|l|}{ Pain/Discomfort } \\
\hline No problems & $680(75.3)$ & $316(72.6)$ & $364(77.8)$ & 0.074 \\
\hline Problems & $223(24.7)$ & $119(27.3)$ & $104(22.2)$ & \\
\hline \multicolumn{5}{|l|}{ Depression/Anxiety } \\
\hline No problems & $782(86.6)$ & $372(85.5)$ & $410(87.6)$ & 0.357 \\
\hline Problems & $121(13.4)$ & $63(14.5)$ & $58(12.4)$ & \\
\hline VAS score, median (IQR) & $80(70-95)$ & $80(70-90)$ & $90(80-100)$ & $<0.0001$ \\
\hline
\end{tabular}


Table 3 Multivariate analyses showing factors associated with the five Health related Quality of Life (EuroQol) domains

\begin{tabular}{|c|c|c|c|c|c|c|c|c|c|c|}
\hline \multirow[b]{2}{*}{ Variable } & \multicolumn{2}{|c|}{ Mobility } & \multicolumn{2}{|c|}{ Selfcare } & \multicolumn{2}{|c|}{ Usual activities } & \multicolumn{2}{|c|}{ Pain/discomfort } & \multicolumn{2}{|c|}{ Anxiety/depression } \\
\hline & OR $(95 \% \mathrm{Cl})$ & $\overline{p \text {-value }}$ & OR $(95 \% \mathrm{Cl})$ & $\overline{p \text {-value }}$ & OR $(95 \% \mathrm{Cl})$ & $\overline{p \text {-value }}$ & OR $(95 \% \mathrm{Cl})$ & $\overline{p \text {-value }}$ & OR $(95 \% \mathrm{Cl})$ & $\overline{p \text {-value }}$ \\
\hline \multicolumn{11}{|l|}{ ART status } \\
\hline ART-naïve vs ART & $3.08(1.63-7.89)$ & 0.007 & $5.21(0.45-60.27)$ & 0.187 & $2.40(0.66-8.75)$ & 0.184 & $1.31(0.88-1.95)$ & 0.184 & $0.88(0.53-1.89)$ & 0.607 \\
\hline \multicolumn{11}{|l|}{ CD4 count, cells/ $\mu \mathrm{L}$} \\
\hline$>200$ vs $\leq 200$ & $1.16(0.55-2.47)$ & 0.697 & $2.93(0.28-30.40)$ & 0.367 & $0.75(0.24-2.37)$ & 0.622 & $0.81(0.54-1.21)$ & 0.311 & $1.14(0.66-1.95)$ & 0.646 \\
\hline Age & $1.02(0.99-1.06)$ & 0.242 & $0.92(0.80-1.06)$ & 0.236 & $0.95(0.89-1.03)$ & 0.208 & $1.01(0.99-1.03)$ & 0.471 & $1.01(0.99-1.04)$ & 0.320 \\
\hline \multicolumn{11}{|l|}{ Gender } \\
\hline Female vs male & $0.44(0.19-1.00)$ & 0.050 & $1.90(0.12-30.97)$ & 0.651 & $2.04(0.39-10.77)$ & 0.401 & $0.83(0.52-1.31)$ & 0.416 & $1.03(0.55-1.91)$ & 0.933 \\
\hline \multicolumn{11}{|l|}{ Education } \\
\hline No education & 1.00 & 1.00 & 1.00 & & 1.00 & & 1.00 & & 1.00 & \\
\hline$\leq$ Grade 12 & $0.37(0.13-1.06)$ & 0.065 & $0.028(0.002-0.309)$ & 0.004 & $0.11(0.02-0.58)$ & 0.009 & $0.90(0.41-1.94)$ & 0.779 & $0.59(0.23-1.51)$ & 0.273 \\
\hline$>$ Grade 12 & $0.41(0.04-4.20)$ & 0.450 & - & - & $0.31(0.02-4.33)$ & 0.382 & $1.14(0.31-4.29)$ & 0.841 & $0.59(0.10-3.52)$ & 0.565 \\
\hline \multicolumn{11}{|l|}{ Employment } \\
\hline Unemployed & 1.00 & & 1.00 & & 1.00 & & 1.00 & & 1.00 & \\
\hline Full or part time or other & $0.71[0.31-1.59]$ & 0.400 & $0.75(0.06-9.54)$ & 0.826 & $0.31(0.02-4.33)$ & 0.458 & $1.34(0.90-2.00)$ & 0.150 & $0.59(0.34-1.04)$ & 0.067 \\
\hline Previous TB & $1.54(0.72-3.28)$ & 0.267 & $2.23(0.25-19.54)$ & 0.469 & $3.10(0.85-11.24)$ & 0.086 & $1.12(0.75-1.66)$ & 0.583 & $0.51(0.30-0.86)$ & 0.012 \\
\hline \multicolumn{11}{|l|}{ BMI category } \\
\hline Not obese & 1.00 & & 1.00 & & 1.00 & & 1.00 & & 1.00 & \\
\hline Obese & $2.78(1.24-6.22)$ & 0.013 & $0.92(0.07-11.63)$ & 0.947 & $1.09(0.27-4.41)$ & 0.906 & $1.20(0.77-1.86)$ & 0.427 & $1.27(0.74-2.17)$ & 0.384 \\
\hline
\end{tabular}


employment housing density, smoking status, ever drank alcohol, previous TB, and BMI category.

The relationship between ART status and HRQoL according to CD4 count strata was examined using Chisquared test for dichotomous outcome variables (EQ-5D five domains) and one-way analysis of variance by ranks (Kruskal-Wallis test) with alpha/(k(k-1)) adjustments for multiple comparisons for the continuous outcome variable (EQ-5D VAS score). The CD4 count strata were categorized as $\leq 200$ cells $/ \mu \mathrm{L}$, and $201-350$ cells $/ \mu \mathrm{L}$, 351-500 cells $/ \mu \mathrm{L}$ and $>500$ cells $/ \mu \mathrm{L}$ according to the recent $\mathrm{WHO}$ recommendations and national guidelines for commencing ART $[30,39,40]$.

All analyses were performed using STATA 11.1 (StataCorp, College Station, Texas, USA). The level of significance for the one-way analysis of variance by ranks (Kruskal-Wallis test) was set at adjusted $\mathrm{P}=0.0009$. However, the level of significance for the other tests was set at $\mathrm{P}<0.05 .95 \%$ confidence intervals were also calculated throughout.

\section{Ethical approval}

The study was approved by the Research Ethics Committee of the Faculty of Health Sciences of the University of Cape Town. Prior to participation in the study, risks and procedures were explained to the subjects, all of whom provided informed consent to participate in the study. The data used for the secondary analysis was delinked from the identity of the study participants.

\section{Results}

\section{Participant characteristics}

The sociodemographic and clinical characteristics, as well as body composition of the participants are presented in Table 1. There were a total of 903 participants (435 were ART- naïve and 468 were on ART). Participants in the ART group were significantly older than in the ART-naive group (median 32 years (IQR 28 - 38) years vs median 35 years (IQR $30-42$ years; $\mathrm{P}<0.0001)$. Three times as many women as men in both groups participated in the study ( $78 \%$ vs $22 \%$ ART, $76 \%$ vs $24 \%$ ART-naive). Both groups were similar for level of education and employment status. The ART-naive group differed significantly from the ART group in terms of housing density $\mathrm{P}=0.002$ ). A higher proportion of patients reported drinking alcohol in the ART group compared to the ART-naive group (52\% vs 43\%; $\mathrm{p}=0.006$ ), but smoking rates did not differ.

The ART group had higher CD4 counts and less cases with a previous history of TB compared to the ARTnaive group $(\mathrm{P}<0.0001$ and $\mathrm{P}<0.001$, respectively). The most common treatment regimen of the subjects on antiretroviral therapy was d4T/3TC/EFV (37\%). The median period on a $\mathrm{d} 4 \mathrm{~T}$-containing regimen among the ART group was 13 months (IQR 8-20 months) and on an AZT-containing regimen was 12 months (IQR 718.5 months).

Measures of body composition showed significant differences between the groups, however, the sum of skinfolds was not different. Subjects in the ART group weighed significantly more $(\mathrm{P}=0.0004)$, had a higher mean $\mathrm{BMI}$ $(\mathrm{P}<0.01)$, greater mean waist-to-hip ratio $(\mathrm{P}<0.0001)$ and greater median sagittal height $(\mathrm{P}<0.0001)$.

\section{Comparison of Health related quality of Life Outcomes by ART status}

The HRQoL outcomes did not differ between groups for self-care, usual activities, pain/discomfort and anxiety/ depression (Table 2). The ART-naïve group, however, experienced a significantly greater problem with mobility than the ART group (9 vs $4 \%, \mathrm{P}<0.05$ ). Multivariate analysis showed no significant differences between groups for self-care, usual activities, pain/discomfort and anxiety/depression (Table 3). In contrast, those in the ART-naive group were 3.08 times more likely to report problems with mobility than those in the ART group (95\% CI 1.37 - 6.94). In addition, those obese were 2.78 times more likely to have increased mobility problems than those not obese (95\% CI 1.24- 6.22).

Table 4 Multivariate analyses showing factors associated with Visual Analogue Scale score

\begin{tabular}{|c|c|c|c|}
\hline Variable & Coefficient & $95 \% \mathrm{Cl}$ & p-value \\
\hline \multicolumn{4}{|l|}{ ART status } \\
\hline ART vs ART-naïve & 5.61 & $2.50-8.72$ & $<0.001$ \\
\hline \multicolumn{4}{|l|}{ CD4 count, cells/ $\mu \mathrm{L}$} \\
\hline$>200$ vs $\leq 200$ & 0.58 & $-2.63-3.79$ & 0.724 \\
\hline Age & -0.034 & $-0.20-0.13$ & 0.682 \\
\hline \multicolumn{4}{|l|}{ Gender } \\
\hline Female vs male & 0.66 & $-2.95-4.26$ & 0.720 \\
\hline \multicolumn{4}{|l|}{ Education } \\
\hline No education & 1.00 & 1.00 & \\
\hline$\leq$ Grade 12 & 0.21 & $-6.07-6.48$ & 0.949 \\
\hline$>$ Grade 12 & -5.12 & $-15.33-5.09$ & 0.325 \\
\hline \multicolumn{4}{|l|}{ Employment } \\
\hline Unemployed & 1.00 & 1.00 & \\
\hline Full or part time or other & 4.76 & $1.63-7.89$ & 0.003 \\
\hline \multicolumn{4}{|l|}{ Housing density } \\
\hline$<1.9$ & 1.00 & 1.00 & \\
\hline$\geq 2$ & 1.76 & $-1.15-4.66$ & 0.236 \\
\hline Previous TB & -2.09 & $-5.20-1.01$ & 0.186 \\
\hline \multicolumn{4}{|l|}{ BMI category } \\
\hline Not obese & 1.00 & 1.00 & \\
\hline Obese & 3.10 & $-0.38-6.57$ & 0.081 \\
\hline
\end{tabular}

Constant 82.04022, R-squared 0.0616, Root MSE 16.106.

All differences were significant at $\mathrm{P}<0.05$. 
The ART-naïve group had a median VAS score of 80 (IQR 70-90), which was lower than that of the ART group (median 90, IQR 80-100; $\mathrm{P}<0.0001$ ). Multivariate analyses showed a 5.61 point increases in VAS score in the ART group compared to ART-naïve group (95\% CI 2.50 8.72; $\mathrm{p}<0.001$ (Table 4). Also, those with some source of income were 4.76 times more likely to have a higher EQ5D VAS score than those unemployed (95\% CI 1.63 -7.89).

Comparison of Health related quality of Life Outcomes by ART status according to CD4 count strata

When grouped according to CD4 count strata, there were no significant associations between ART-naïve and
ART groups in most of the EQ-5D domains (Table 5). However, the ART-naïve group indicated having significantly greater problems under the CD4 count of $>500$ cells $/ \mu \mathrm{L}$ in the anxiety/depression domain $(22.4 \%$ vs $8.8 \%$, $\mathrm{p}=0.018)$ and significantly lower EQ-5D VAS scores under the CD4 counts of $\leq 200$ cells $/ \mu \mathrm{L}$ (median 80 (IQR 60-90) vs 90 (IQR 80-100), $\mathrm{p}=0.0003$ ) and 201-350 cells/ $\mu \mathrm{L}$ (median 80 (IQR 70-90) vs 90 (80-100).

\section{Discussion}

In this study that compared HRQoL outcomes between ART-naive and patients on ART for 6 months or longer (who were mostly using a d4T-based first-line regimen)

Table 5 Subjects reporting problems in the EQ-5D dimensions (\%) and median EQ VAS score by ART status across CD4 count strata

\begin{tabular}{|c|c|c|c|c|}
\hline & $\begin{array}{l}\text { Total } \\
\text { N (\%) }\end{array}$ & $\begin{array}{c}\text { ART-naïve } \\
\text { N (\%) }\end{array}$ & $\begin{array}{c}\text { ART } \\
\text { N (\%) }\end{array}$ & $P$ value \\
\hline \multicolumn{5}{|c|}{ Mobility (CD4 count, cells/ $\mu \mathrm{L}$ ) } \\
\hline$\leq 200$ & $16(6.9)$ & $14(8.6)$ & $2(2.9)$ & 0.113 \\
\hline 201-350 & $13(5.4)$ & $6(6.0)$ & $7(5.0)$ & 0.736 \\
\hline $351-500$ & $6(3.9)$ & $3(4.7)$ & $3(3.3)$ & 0.649 \\
\hline$>500$ & $16(10.3)$ & $10(13.2)$ & $6(7.5)$ & 0.244 \\
\hline \multicolumn{5}{|l|}{ Self care } \\
\hline$\leq 200$ & $1(0.4)$ & $1(0.61)$ & $0(0.0)$ & 0.511 \\
\hline 201-350 & $1(0.4)$ & $1(1.0)$ & $0(0.0)$ & 0.236 \\
\hline $351-500$ & $1(0.6)$ & $0(0.0)$ & $1(1.1)$ & 0.403 \\
\hline$>500$ & $3(1.9)$ & $3(4.0)$ & $0(0.0)$ & 0.073 \\
\hline \multicolumn{5}{|c|}{ Usual activities } \\
\hline$\leq 200$ & $6(2.6)$ & $6(3.7)$ & $0(0.0)$ & 0.104 \\
\hline 201-350 & $4(1.7)$ & $2(2.0)$ & $2(1,4)$ & 0.733 \\
\hline $351-500$ & $2(1.3)$ & $0(0.0)$ & $2(2.0)$ & 0.235 \\
\hline$>500$ & $4(2.6)$ & $3(4.0)$ & $1(1.3)$ & 0.281 \\
\hline \multicolumn{5}{|c|}{ Pain/discomfort } \\
\hline$\leq 200$ & $68(29.2)$ & $50(30.7)$ & $18(25.7)$ & 0.445 \\
\hline 201-350 & $53(22.1)$ & $27(27.0)$ & $26(18.6)$ & 0.121 \\
\hline $351-500$ & $34(21.8)$ & $12(18.8)$ & $22(23.9)$ & 0.442 \\
\hline$>500$ & $42(26.9)$ & $22(29.0)$ & $20(25.0)$ & 0.578 \\
\hline \multicolumn{5}{|c|}{ Depression/anxiety } \\
\hline$\leq 200$ & $32(13.7)$ & $22(13.5)$ & $10(14.3)$ & 0.873 \\
\hline 201-350 & $33(13.8)$ & $10(10.0)$ & $23(16.4)$ & 0.154 \\
\hline $351-500$ & $18(11.5)$ & $7(10.9)$ & $11(12.0)$ & 0.845 \\
\hline$>500$ & $24(15.4)$ & $17(22.4)$ & $7(8.8)$ & 0.018 \\
\hline \multicolumn{5}{|c|}{ VAS score, median (IQR) } \\
\hline$\leq 200$ & $80(70-90)$ & $80(60-90)$ & $90(80-100)$ & 0.0003 \\
\hline 201-350 & $90(70-95)$ & $80(70-90)$ & $90(80-100)$ & 0.0004 \\
\hline $351-500$ & $90(80-100)$ & $82.5(80-100)$ & $90(77.5-100)$ & 0.455 \\
\hline$>500$ & $80(70-90)$ & $80(70-90)$ & $90(80-100)$ & 0.004 \\
\hline
\end{tabular}


the key findings were: Subject's EQ-VAS scores (representing the subject's self-rated health state) improved significantly on ART; and when subjects were grouped according to their baseline CD4 counts, EQ-VAS scores were significantly lower in ART-naïve patients with CD4 counts $\leq 200$ cells $/ \mu \mathrm{L}$ and $201-350$ cells $/ \mu \mathrm{L}$.

Our finding that study subject's EQ-5D VAS scores improved significantly on ART, suggests that drug toxicities, especially those related to $\mathrm{d} 4 \mathrm{~T}$ have little impact on subects self-rated health. This study, therefore, support the findings of several studies [9-12] which report improved HRQoL outcomes on ART, despite participants being national first-line regimens containing $\mathrm{d} 4 \mathrm{~T}$ with known toxicities [14-25]. The study by Pitt and colleagues [9], for example, showed that drug toxicities, mainly those related to $\mathrm{d} 4 \mathrm{~T}$, had little impact on mental health HRQoL scores during the first 48 weeks on ART.

We also found that, when subjects were grouped according to their baseline CD4 counts, EQ-VAS scores were significantly lower in ART-naïve patients with CD4 counts $\leq 200$ cells $/ \mu \mathrm{L}$ and $201-350$ cells $/ \mu \mathrm{L}$. Our study findings corroborate recently reported studies. Mathews and colleagues found that EQ-5D VAS score improved with increasing CD4 cell count strata and were 65.4, 70 and 75 for CD 4 counts $<50,50-199$ and $\geq 200$ cells $/ \mu \mathrm{L}$ [41]. Anis and colleagues [42] showed that improvements in CD4 cell counts were associated with higher HRQoL scores $(P=0.08)$. Bhargava and colleagues [13] found the HRQoL of patients receiving ART increased significantly with improvement in CD4 count. Igumbor and colleagues [7] found weak but significant associations between CD4 cell counts and HRQoL in a cohort of treatment-naïve patients and those who had received ART for 12 months.

The strength of this study was the large sample size of HIV-infected individuals derived from a primary care clinic and it is one of the few studies that shed light on the impact of higher CD4 cell counts on HRQoL. However, the results of the study may only be generalizable to the study population and other similar settings. Our finding that the EQ-5D VAS was sensitive to ART use and ART eligibility (based on CD4 cell count) supports the use of this particular instrument in future assessments of HRQoL outcomes among HIV infected individuals in South Africa.

The study had the several limitations. Because this was a non-randomized study, the associations observed in the study are potentially biased due to residual confounding. We could not adjust for HIV-related symptom burden, duration on ART (among those on ART) and HIV-RNA viral load levels because all these factors known to influence HRQoL among HIV infected individuals [38] were not assessed in the present study. Furthermore, there may be limitations to the generalizability of study findings due to the CD4 count categories used in this study.

\section{Conclusions}

In conclusion, the study data suggest that ART is effective in improving the HRQoL (that is, self-rated health state), including those subjects who were immunocompromised, which may be applicable to ART eligibility of the public sector ART program in South Africa. Further research is needed to examine the impact that long term ART use has on the HRQoL of HIV-infected people, as well as looking at long term government strategies to improve HIV-infected patient's general health perception during the course of lifelong ART.

\section{Abbreviations \\ HIV: Human immunodeficiency virus; ART: Antiretroviral therapy; HRQoL: Health-related quality of life; EQ-5D: EuroQol five domains questionnaire; EQ-5D VAS: EuroQol visual analogue scale; d4T: Stavudine; 3TC: Lamuvidine; 3TC: Efavirenz; AZT: Zidovudine; NVP: Nevaripine.}

\section{Competing interests}

The authors declare that that they have no competing interests.

\section{Authors' contributions}

MDN, SJW, VEL designed the study. MDN with input from SJW and VEL analyzed the data. MDN and SJW wrote the paper with input from all the authors who each approved the final version.

\section{Acknowledgements}

This study was supported by the World Diabetes Foundation, South African Department of Health, and the Faculty of Health Sciences, University of Cape Town.

\section{Author details}

'MRC/UCT Research Unit for Exercise Science and Sports Medicine, Department of Human Biology, University of Cape Town, Cape Town, South Africa. ${ }^{2}$ Department of Sport Management, Human Performance Laboratory, Cape Peninsula University of Technology, Cape Town, South Africa. ${ }^{3}$ Division of Diabetic Medicine and Endocrinology, Department of Medicine, University of Cape Town, Cape Town, South Africa. ${ }^{4}$ Chronic Disease Initiative for Africa (CDIA), Cape Town, South Africa.

Received: 20 December 2013 Accepted: 19 June 2014

Published: 3 July 2014

\section{References}

1. UNAIDS: Report on the global AIDS rpidemic 2013. Joint United Nations Programme on HIV/AIDS. 2013. http://www.unaids.org/en/ media/unaids/contentassets/documents/epidemiology/2013/gr2013/ UNAIDS_Global_Report_2013_en.pdf.

2. World Health Organization: Global update on HIV treatment 2013: results, impact and opportunities: WHO report in partnership with UNICEF and UNAIDS. In Geneva: World Health Organization; 2013. http://apps.who.int/ iris/bitstream/10665/85326/1/9789241505734_eng.pdf.

3. Carr A, Hudson J, Chuah J, Mallal S, Law M, Hoy J, Doong N, French M Smith D, Cooper DA: HIV protease inhibitor substitution in patients with lipodystrophy: a randomized, controlled, open-label, multicentre study. Aids 2001, 15:1811-1822.

4. Hadigan C, Meigs JB, Corcoran C, Rietschel P, Piecuch S, Basgoz N, Davis B, Sax P, Stanley T, Wilson PWF: Metabolic abnormalities and cardiovascular disease risk factors in adults with human immunodeficiency virus infection and lipodystrophy. Clinical Infectious Diseases 2001, 32:130-139.

5. Bradbury RA, Samaras K: Antiretroviral therapy and the human immunodeficiency virus-improved survival but at what cost? Diabetes Obes Metab 2008, 10:441-450.

6. Mutimura E, Stewart A, Rheeder P, Crowther NJ: Metabolic function and the prevalence of lipodystrophy in a population of HIV-infected African subjects receiving highly active antiretroviral therapy. J Acquir Immune Defic Syndr 2007, 46:451-455. 
7. lgumbor J, Stewart A, Holzemer W: Comparison of the health-related quality of life, CD4 count and viral load of AIDS patients and people with HIV who have been on treatment for 12 months in rural South Africa. Sahara J 2013, 10:25-31.

8. Mclnerney PA, Ncama BP, Wantland D, Bhengu BR, McGibbon C, Davis SM, Corless IB, Nicholas PK: Quality of life and physical functioning in HIVinfected individuals receiving antiretroviral therapy in KwaZulu-Natal, South Africa. Nurs Health Sci 2008, 10:266-272.

9. Pitt J, Myer L, Wood R: Quality of life and the impact of drug toxicities in a South African community-based antiretroviral programme. J Int AIDS Soc 2009, 12:5.

10. Louwagie GM, Bachmann MO, Meyer K, Booysen FR, Fairall LR, Heunis C: Highly active antiretroviral treatment and health related quality of life in South African adults with human immunodeficiency virus infection: A cross-sectional analytical study. BMC Public Health 2007, 7:244.

11. Jelsma J, Maclean E, Hughes J, Tinise X, Darder M: An investigation into the health-related quality of life of individuals living with HIV who are receiving HAART. AIDS care 2005, 17:579-588.

12. Wouters E, Van Loon F, Van Rensburg D, Meulemans H: State of the ART: clinical efficacy and improved quality of life in the public antiretroviral therapy program, Free State province, South Africa. AIDS Care 2009, 21:1401-1411.

13. Bhargava A, Booysen Fle R: Healthcare infrastructure and emotional support are predictors of CD4 cell counts and quality of life indices of patients on antiretroviral treatment in Free State Province, South Africa. AIDS Care 2010, 22:1-9.

14. Anastos K, Lu D, Shi Q, Tien PC, Kaplan RC, Hessol NA, Cole S, Vigen C, Cohen M, Young M, Justman J: Association of serum lipid levels with HIV serostatus, specific antiretroviral agents, and treatment regimens. J Acquir Immune Defic Syndr 2007, 45:34-42.

15. Domingos H, Cunha RV, Paniago AM, Martins DM, Elkhoury EB, Souza AS: Metabolic effects associated to the highly active antiretroviral therapy (HAART) in AIDS patients. Braz J Infect Dis 2009, 13:130-136.

16. van Griensven J, Zachariah R, Rasschaert F, Mugabo J, Atte EF, Reid T: Stavudine- and nevirapine-related drug toxicity while on generic fixed-dose antiretroviral treatment: incidence, timing and risk factors in a three-year cohort in Kigali, Rwanda. Trans R Soc Trop Med Hyg 2010, 104:148-153.

17. Murphy RA, Sunpath $H$, Kuritzkes DR, Venter F, Gandhi RT: Antiretroviral therapy-associated toxicities in the resource-poor world: the challenge of a limited formulary. J Infect Dis 2007, 196(Suppl 3):S449-456.

18. Ait-Mohand $H$, Bonmarchand $M$, Guiguet $M$, Slama L, Marguet F, Behin A, Amellal B, Bennai Y, Peytavin G, Calvez V, Pialoux G, Murphy R, Katlama C: Viral efficacy maintained and safety parameters improved with a reduced dose of stavudine: a pilot study. HIV Med 2008, 9:738-746.

19. Cournil A, Coudray M, Kouanfack C, Essomba CN, Tonfack CA, Biwole-Sida M, Delaporte E, Bork K, Laurent C: Reduced dose of stavudine and lipoatrophy in HIV-infected patients in Cameroon. Antivir Ther 2010, 15:1039-1043.

20. Pedrol E, Martin T, del Pozo MA, Flores J, Sanz J, Carton JA, Jusdado JJ, Arazo P, Ribera E, Deig E: Efficacy and safety of a reduced-dose of stavudine in HIV-infected patients under immunological and virological stable conditions. Med Clin (Barc) 2007, 129:361-365.

21. Hanvanich $M$, Prasanthai $V$, Riengchan $P$, Arunyingmongkol $K$, Intalapaporn P, Hiransuthikul N, Suankratay C, Kulwichit W: Reduction of D4T Dosage Improves Lipoatrophy Without Virologic Failure. In Proceedings of the 2nd IAS Conference on HIV Pathogenesis and Treatment. Paris; 2003. Abstract no.749.

22. Delpierre C, Cuzin L, Alvarez M, Khatibi S, Bonnet E, Obadia M, Massip P: Lowering stavudine dosages does not compromise anti-viral efficacy in HIV-1 infected patients. In Proceedings of the 9th European AIDS Conference; 2003. Abstract no.262.

23. Koegl C, Wolf E, Postel N, Buchberger A, Ruemmelein N, Jaegel-Guedes $E_{\text {, }}$ Jaeger H: Low Dose Stavudine: As Effective as Standard Dose but Less Side Effects. In Proceedings of the 9th European AIDS Conference; 2003. Abstract no.284.

24. Urbina A, Jibilian A, Nibbe Y, Maa JF, Wang S: Long Term Use of Low dose Stavudine is Effective and Well Tolerated. In Proceedings of the 3rd IAS Conference on HIV Pathogenesis and Treatment; 2005. Abstract no. TuPe2.2B31.

25. Ribera E, Paradiñeiro JC, Domingo P, Sauleda S, Luque S, Garcia-Arumi E, Feijoo M, Fontanet A, Falco V, Crespo M, Ocana I, Sureda D, Planas M,
Pahissa A: A Randomized Study Comparing the Efficacy and Tolerability of Lowdose versus Standard-dose Stavudine in Antiretroviral-naïve patients (ETOX Study). In Proceedings of the 3rd IAS Conference on HIV Pathogenesis and Treatment. 2005. Abstract no. TuPe2.4 C10.

26. World Health Organization: Antiretroviral therapy for HIV infection in adults and adoloscents. Geneva: World Health Organization; 2010.

27. Gallant JE, Staszewski S, Pozniak AL, DeJesus E, Suleiman JM, Miller MD, Coakley DF, Lu B, Toole JJ, Cheng AK: Efficacy and safety of tenofovir DF vs stavudine in combination therapy in antiretroviral-naive patients: a 3-year randomized trial. Jama 2004, 292:191-201.

28. World Health Organization: March 2014 supplement to the 2013 consolidated guidelines on the use of antiretroviral drugs for treating and preventing HIV infection:Recommendations for a public health approach. Geneva: World Health Organization; 2014. http://apps.who.int/ iris/bitstream/10665/104264/1/9789241506830_eng.pdf.

29. Jouquet G, Bygrave H, Kranzer K, Ford N, Gadot L, Lee J, Hilderbrand K, Goemaere E, Vlahakis N, Trivino L, Makakole L, Cleary S: Cost and costeffectiveness of switching from d4T or AZT to a TDF-based first-line regimen in a resource-limited setting in rural Lesotho. J Acquir Immune Defic Syndr 2011, 58:e68-74.

30. National Department of Health: National Antiretroviral Treatment Guidelines. Pinetown, South Africa: Jacana Publishers; 2004.

31. Dave JA, Lambert EV, Badri M, West S, Maartens G, Levitt NS: Effect of nonnucleoside reverse transcriptase inhibitor-based antiretroviral therapy on dysglycemia and insulin sensitivity in South African HIV-infected patients. J Acquir Immune Defic Syndr 2011, 57:284-289.

32. Harrison GG, Buskirk ER, Carter JEL, Johnston FE, Lohman TG, Pollock ML, Roche AF, Wilmore J: Skinfold Thicknesses and Measurement Technique In Anthropometric Standardization Reference Manual. 2nd edition. Edited by Lohman TG, Roche AF, Martorel R. 1988:55-80.

33. Venter E, Gericke GJ, Bekker PJ: Nutritional status, quality of life and CD4 cell count of adults living with HIV/AIDS in the Ga-Rankuwa area (South Africa). S Afr J Clin Nutr 2009, 22:124-129.

34. Durnin JV, Womersley J: Body fat assessed from total body density and its estimation from skinfold thickness: measurements on 481 men and women aged from 16 to 72 years. Br J Nutr 1974, 32:77-97.

35. Sampaio LR, Simoes EJ, Assis AM, Ramos LR: Validity and reliability of the sagittal abdominal diameter as a predictor of visceral abdominal fat. Ara Bras Endocrinol Metabol 2007, 51:980-986.

36. Badia Llach $X$, Herdman M, Schiaffino A: Determining correspondence between scores on the EQ-5D "thermometer" and a 5-point categorical rating scale. Med Care 1999, 37:671-677.

37. Delate T, Coons SJ: The use of 2 health-related quality-of-life measures in a sample of persons infected with human immunodeficiency virus. Clin Infect Dis 2001, 32:E47-52.

38. Gakhar H, Kamali A, Holodniy M: Health-related quality of life assessment after antiretroviral therapy: a review of the literature. Drugs 2013, 73:651-672.

39. World Health Organization: Consolidated guidelines on the use of antiretroviral drugs for treating and preventing HIV infection: Recommendations for a public health approach June 2013. Geneva: World Health Organization; 2013. http://apps.who.int/iris/bitstream/10665/ 85321/1/9789241505727_eng.pdf.

40. National Department of Health: Clinical Guidelines for the Management of HIV\&AIDS in Adults and Adolescents. Pretoria: National Department of Health; 2010.

41. Mathews WC, May S: EuroQol (EQ-5D) measure of quality of life predicts mortality, emergency department utilization, and hospital discharge rates in HIV-infected adults under care. Health Qual Life Outcomes 2007, 5:5.

42. Anis AH, Nosyk B, Sun H, Guh DP, Bansback N, Li X, Barnett PG, Joyce V, Swanson KM, Kyriakides TC, Holodniy M, Cameron DW, Brown ST, OPTIMA Team1: Quality of life of patients with advanced HIV/AIDS: measuring the impact of both AIDS-defining events and non-AIDS serious adverse events. J Acquir Immune Defic Syndr 2009, 51:631-639.

\section{doi:10.1186/1471-2458-14-676}

Cite this article as: Nglazi et al:: Quality of life in individuals living with HIV/AIDS attending a public sector antiretroviral service in Cape Town, South Africa. BMC Public Health 2014 14:676. 